\title{
Prevalence of Malocclusion Among Adolescents In Central Anatolia
}

\author{
İbrahim Erhan Gelgöra, \\ Ali İhya Karaman ${ }^{\text {, }}$ \\ Ertuḡrul Ercanc
}

\begin{abstract}
Objectives: The objective of this study was to describe the prevalence of malocclusion in a population of Central Anatolian adolescents in relation to gender.

Methods: The sample comprised 2329 teenagers (1125 boys and 1204 girls), aged between 12 and 17 years (mean age: $14.6 \mathrm{yrs}$ ). Occlusal anteroposterior relationships were assessed using the Angle classification. Other variables examined were overjet, overbite, crowding, midline diastema, posterior crossbite, and scissors bite.

Results: The results showed that about $10.1 \%$ of the subjects had normal occlusions, $34.9 \%$ of the subjects had Class I malocclusions, 40.0\% had Class II Division 1 malocclusions, $4.7 \%$ had Class II Division 2 malocclusions and $10.3 \%$ had Class III malocclusions. Over $53.5 \%$ had normal overbites, and $18.3 \%, 14.4 \%, 5.6 \%$, and $8.2 \%$ had increased, reduced, edge-to-edge or anterior open bite values, respectively. Overjet relationship was normal in $58.9 \%$, increased in $25.1 \%$, reversed in $10.4 \%$, and edge-to-edge in $5.6 \%$. A posterior crossbite registered in $9.5 \%$ and scissors bite in $0.3 \%$. Anterior crowding was present in $65.2 \%$ of the sample and midline diastema in $7.0 \%$. No clear gender differences were noted, except for normal overbite (most frequent in girls, $\mathrm{P}<.001$ ) and increased overbite (most frequent in boys, $\mathrm{P}<.05$ ).

Conclusions: Class II Division 1 malocclusion is the most prevalent occlusal pattern among the Central Anatolian adolescents and the high values $(25.1 \%$ and $18.3 \%)$ of increased overjet and overbite were a reflection of the high prevalence of Class II malocclusion. (Eur J Dent 2007;1:125-131)
\end{abstract}

Key words: Malocclusion; Class I malocclusions; Class II Division 1; Class III malocclusions.

\section{INTRODUCTION}

A large number of studies on the prevalence of malocclusion in different populations have been

n. a PhD, Assistant Professor, Department of Orthodontics, School of Dentistry, Kirikkale University, Kirikkale, Turkey.

b Professor, Department of Orthodontics, School of Dentistry, Selcuk University, Konya, Turkey. PhD, Assistant Professor, Department of Operative Dentistry, School of Dentistry, Kirikkale University, Kirikkale, Turkey.

- Corresponding Author: Dr. Ertugrul ERCAN Kirikkale University, Faculty of Dentistry, Department of Operative Dentistry, 71100 Merkez, Kirikkale TURKEY E-mail: ertugrulercanßahotmail.com published. ${ }^{1-10}$ Since the early 1900's, when orthodontics became a recognized specialty of the dental profession, much has been written on the incidence and/or prevalence of malocclusion in the different populations. $14,4,11$

Different ethnic groups have been investigated; including, Amerindian, 2,3 Caucasian, ${ }^{4,5}$ non-Hispanic black, ${ }^{6-9}$ non-Hispanic white, ${ }^{8}$ and Italian. ${ }^{10}$ Analysis of the prevalence of occlusal traits in isolated human populations can provide valuable information regarding the aetiology of malocclusions and other complex traits. ${ }^{11}$ The reported incidences vary from 30 to 93 percent, making it clear that the majority of children have irregular teeth. This divergence in prevalence figures may 
depend on differences for specific ethnic groups, but also on wide ranges in number, as well as in age, among the subjects examined. However, differences in registration methods, i.e. the criteria for the recorded items, are probably the most important factors explaining this differences. ${ }^{3}$

There are several methods that may be used to evaluate, describe and classify occlusion. These can be classified basically as qualitative and quantitative. ${ }^{12}$ Qualitative variables define only the presence or absence of a selected malocclusion criterion. A series of malocclusion studies have been undertaken using qualitative methods of assessment. ${ }^{4,13-15}$

The most examined topics are antero-posterior relationships. 3,16,17 Angle's classification has been widely used as a qualitative epidemiological tool for malocclusion assessment. ${ }^{17}$

Despite the amount of literature on the subject, which has been summarized by Thilander et $\mathrm{al}^{3}{ }^{3}$ there are few epidemiologic studies on Turks. ${ }^{18-}$ 20 The aim of the present survey was, therefore, to document the prevalence of individual traits of malocclusion, including sagittal relationship, overbite-open bite, overjet, posterior crossbitescissors bite, irregularity score for upper and lower incisors, and midline diastema, in a sample of Central Anatolian adolescents aged 12-17 years who are representing most common orthodontic treatment age group. Furthermore, the association between gender and the above traits was evaluated. The documents will be useful for the forecasts of the need for orthodontic treatment among Turkish population which is important for planning public orthodontic and dental services, and to show the way for further works needed to be done regarding aetiology and/or environmental and genetic interactions.

\section{MATERIALS AND METHODS}

A sample of 2329 subjects 11125 males, 1204 females; age range, 12.5-17.4 years; mean age, 14 years and 6 months) was randomly selected from a population that attended the Dental Health Center of Kırıkkale in the centre of Anatolia, Turkey. The sample was derived from general dental health control demanded subjects not only seeking the orthodontic treatment. The examinations were carried out in the oral diagnosis clinics. Family origin, registered in order to determine the Turkish racial composition of the sample, was found to be representative of Anatolian ancestry from the central part of the country. All male and female patients who met the following criteria were included in the sample: (1) age 12 to 18 years, (2) secondary dentition present with no remaining deciduous teeth, (3) no multiple missing teeth, (4) presence of first permanent molars and canines, and (5) no previous history of orthodontic treatment. Each examination took place while the subject was sitting in a dental chair. Findings were classified in the following categories;

Occlusal anteroposterior relationships: Normal occlusion, Class I malocclusion, Class II Division 1, Class II Division 2, and Class III malocclusion. Patients with an occlusal pattern that deviated from the Class I relationship as described by Angle, ${ }^{21}$ (including crowding, spacing, rotations and abnormal overbite and overjet) were categorized as Class I malocclusion. Thus, the Class I normal category was limited to patients with occlusions that were ideal or near ideal. Patients with a different Angle classification of occlusion on each side were categorized into a single class based on the predominant pattern of occlusion and/or canine relationship. . $^{3,17,22}$

The overbite was considered normal if the maxillary central incisors overlapped the incisal third of the crown of the mandibular central incisors. The overbite was classified as increased if the overlap exceeded the middle third of the crown of the mandibular central incisors and reduced if it was less than incisal third of the crown. An edgeto-edge incisor relationship was noted if the maxillary and mandibular incisors occluded on their incisal edges. Anterior open bite was diagnosed when there was a vertical gap between the maxillary and mandibular incisor edges with the teeth in centric occlusion. ${ }^{3,17}$

Overjet was defined as the horizontal distance in millimeters between the labial surfaces of the maxillary and mandibular central incisors. For this purpose, the subject was positioned with the Frankfort plane horizontal, and the distance was measured with a ruler. Overjet values between 2 and $3 \mathrm{~mm}$ were considered normal, greater than $3 \mathrm{~mm}$ was considered increased, and less than 1 $\mathrm{mm}$ was taken as edge to edge. The term negative overjet was used if both the left and right maxillary central incisors were in lingual occlusion. 3,17 
Posterior crossbite and scissors bite were registered as bilateral, right and left. ${ }^{3,23}$ Anterior crowding was recorded for the incisor segment of each jaw (1-3 mm=mild; 4-6 mm=moderate; >6 $\mathrm{mm}=$ severe). ${ }^{3,17}$ Midline diastema was diagnosed when there was a space of at least $1 \mathrm{~mm}$ between the central incisors in either arch. ${ }^{3,17}$ The examinations were completed in about one and a half years by the same examiner (IEG). Intraexaminer reliability, tested by re-examining 40 subjects after an interval of 2 to 4 weeks, was high ( $r=0.95)$.

\section{Statistical analysis}

The ratio of the sample, as a maximum estimate of the proportion of individual traits of malocclusion in the whole population was calculated for the total sample and for girls and boys separately. Number of subjects with diagnosed anomaly (n) and its prevalence (n/N x 100, where $\mathrm{N}$ is the number of subjects examined) was determined. The data were coded, entered into a computer, and analyzed with the SPSS software package (version 13.0, SPSS Inc., Chicago, III., USA). The chi-square statistic was used to assess the statistical significance between boys and girls while taking $P$ values of less than 0.05 as statistically significant.

Table 1. Occlusal classifications.

\begin{tabular}{lcccccccc}
\hline \multirow{2}{*}{$\begin{array}{l}\text { Occlusal anteroposterior } \\
\text { relationships }\end{array}$} & \multicolumn{2}{c}{ Boys } & \multicolumn{2}{c}{ Girls } & \multicolumn{3}{c}{ Total } & \multirow{2}{*}{ P } \\
\cline { 2 - 7 } & $\mathrm{n}$ & $\%$ & $\mathrm{n}$ & $\%$ & $\mathrm{n}$ & $\%$ & \\
\hline Normal Occlusion & 110 & 9.8 & 126 & 10.5 & 236 & 10.1 & NS & 0.630 \\
Class I & 404 & 35.9 & 408 & 33.9 & 812 & 34.9 & NS & 0.317 \\
Class II Division 1 & 448 & 39.8 & 483 & 40.1 & 931 & 40.0 & NS & 0.899 \\
Class II Division 2 & 56 & 5.0 & 54 & 4.5 & 110 & 4.7 & NS & 0.625 \\
Class III & 107 & 9.5 & 133 & 11.0 & 240 & 10.3 & NS & 0.246 \\
Total & 1125 & 100.0 & 1204 & 100.0 & 2329 & 100.0 & & \\
\hline
\end{tabular}

NS: Not significant.

Table 2. Distribution of overbite.

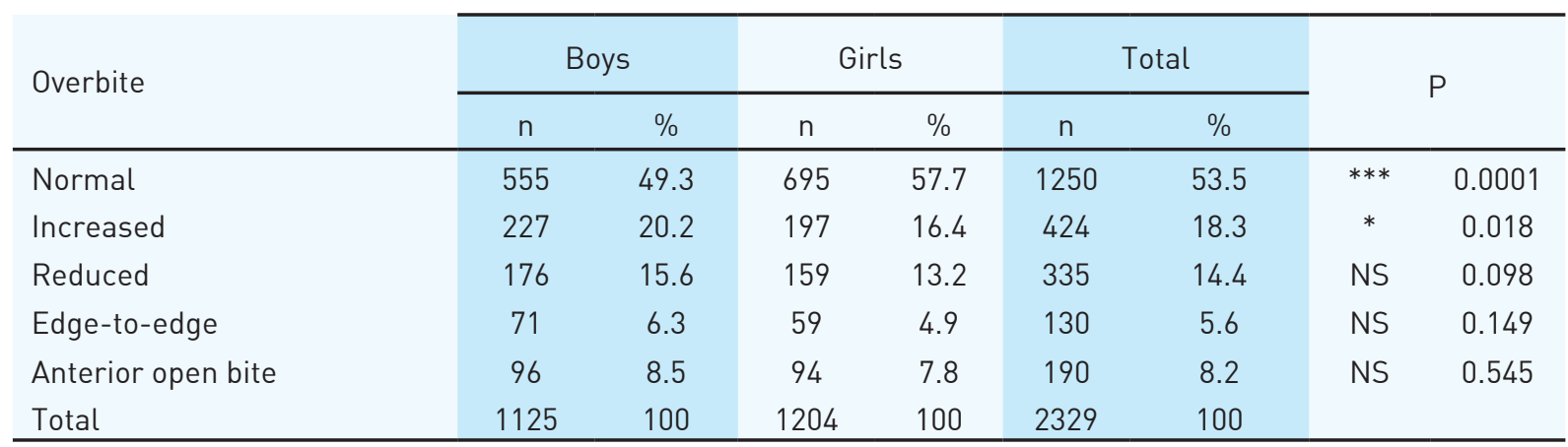

NS: Not significant; ${ }^{*}: \mathrm{P}<.05 ;{ }^{* * *}: \mathrm{P}<.001$.

\section{RESULTS}

As will be noted from Table 1, Class I malocclusion was found in 812 subjects, which represented $34.9 \%$ of the 2329 individuals examined. Class II malocclusion was diagnosed in 1041 individuals; $40.0 \%$ of all patients were Division 1 and $4.7 \%$ of all patients were Division 2. Class III malocclusion was found in 240 subjects (10.3\%).

Distribution of overbite is shown in Table 2. Normal overbite was the most common (53.5\%), mostly observed in girls ( $P<.001)$. Increased overbite was recorded in $18.3 \%$, mostly observed in boys $(P<.05)$. The prevalence of edge-to-edge and anterior open bite values were found in $5.6 \%$ and $8.2 \%$, respectively.

Normal overjet was diagnosed in 1371 individuals (58.9\%) (Table 3). Prevalence of increased overjet $(25.1 \%)$ was found to be higher than negative overjet $(10.4 \%)$ and edge to edge $(5.6 \%)$ values.

Crossbite was found more frequently on the right than left side, but occurred on both sides in $4.0 \%$. Scissors bite was rare, being recorded in only $0.3 \%$ of the subjects (Table 4 ).

Anterior crowding was diagnosed in 1638 individuals (65.2\%) (Table 5). 17.9, 9.1 and $38.1 \%$ of 
those had crowding in the upper arch, the lower arch and both arches, respectively. Moderate crowding was found more frequently in both arches.

Midline diastema was found in $7.0 \%$ of the sample. It was observed mostly in girls, but no statistically significant relationship was found (Table 6).

\section{DISCUSSION}

Although many studies have been published that describe the prevalence and types of malocclusion, it is difficult to compare and contrast these findings; in part, because of the varying methods and indices used to assess and record occlusal relationships, age differences of the study populations, examiner subjectivity, specific objectives, and differing sample sizes. ${ }^{22}$ The method used in this study was collected from different studies. 3,10,17,22 Our results will be discussed with the findings from other geological regions because there have been few epidemiologic surveys in Turkey. Güray et $\mathrm{al}^{18}$ used the Treatment Priority Index, and found $72.26 \%$ of 483 primary school students from Konya district (Anatolia) required orthodontic treatment. Uḡur et $\mathrm{al}^{20}$ found a $59.62 \%$ prevalence of malocclusions in 6-10-year-old 572
Turkish primary school children in Anatolia. Gelgor et $\mathrm{al}^{19}$ only investigated prevalence of hypodontic and dimensional anomalies in adolescent teeth. Our study included a wide adolescent sample and malocclusion was found in $89.9 \%$ (Table 1). This rate was higher than reported by Güray et $\mathrm{al}^{18}$ and Ugur et al. ${ }^{20}$ This higher rate could have arisen from the large number of examined persons and different age group according to the other studies. ${ }^{18-20}$ Ugur et $\mathrm{al}^{20}$ and Proffit et al ${ }^{24}$ have reported that orthodontic treatment needs increases with age. Also age group of our study population was higher than the other studies. ${ }^{18-20}$

Although Angle's classification is limited in that it does not incorporate vertical and transverse abnormalities, it is a universally accepted system that is reliable and repeatable and minimizes examiner subjectivity. ${ }^{17}$ In this study, Class I malocclusion was found in $34.9 \%$ of the sample. This Class I occlusion figure included individuals with incisor crowding and dental malalignment and thus did not imply ideal Class I occlusion. Onyeaso ${ }^{17}$ found that Class I malocclusion was more common in Nigerian adolescents (50\%). In a study by Silva and Kang, ${ }^{22}$ Latin adolescents demonstrated a higher rate of Class I malocclusion of $69.4 \%$.

Table 3. Distribution of overjet.

\begin{tabular}{lcccccccc}
\cline { 2 - 7 } Overjet & \multicolumn{2}{c}{ Boys } & \multicolumn{2}{c}{ Girls } & \multicolumn{3}{c}{ Total } & \multirow{2}{*}{$\mathrm{P}$} \\
\cline { 2 - 7 } & $\mathrm{n}$ & $\%$ & $\mathrm{n}$ & $\%$ & $\mathrm{n}$ & $\%$ & \\
\hline Normal & 660 & 58.7 & 711 & 59.1 & 1371 & 58.9 & $\mathrm{NS}$ & 0.866 \\
Increased & 281 & 25.0 & 304 & 25.2 & 585 & 25.1 & $\mathrm{NS}$ & 0.886 \\
Negative & 113 & 10.0 & 130 & 10.8 & 243 & 10.4 & NS & 0.588 \\
Edge-to-edge & 71 & 6.3 & 59 & 4.9 & 130 & 5.6 & NS & 0.149 \\
Total & 1125 & 100 & 1204 & 100 & 2329 & 100 & & \\
\hline
\end{tabular}

NS: Not significant.

Table 4. Distribution of posterior crossbite and scissors bite.

\begin{tabular}{|c|c|c|c|c|c|c|c|c|c|c|}
\hline & & & \multirow{2}{*}{\multicolumn{2}{|c|}{ Boys }} & \multirow{2}{*}{\multicolumn{2}{|c|}{ Girls }} & \multirow{2}{*}{\multicolumn{2}{|c|}{ Total }} & \multirow{3}{*}{\multicolumn{2}{|c|}{$P$}} \\
\hline & & & & & & & & & & \\
\hline & & & $n$ & $\%$ & $n$ & $\%$ & $\mathrm{n}$ & $\%$ & & \\
\hline \multirow{5}{*}{ Crossbite } & \multicolumn{2}{|l|}{ No finding } & 1021 & 90.8 & 1082 & 89.9 & 2103 & 90.3 & NS & 0.677 \\
\hline & \multicolumn{2}{|l|}{ Bilateral } & 41 & 3.6 & 52 & 4.3 & 93 & 4.0 & NS & 0.544 \\
\hline & \multirow{2}{*}{ Unilateral } & right & 35 & 3.1 & 41 & 3.4 & 76 & 3.3 & NS & 0.890 \\
\hline & & left & 24 & 2.1 & 27 & 2.2 & 51 & 2.2 & NS & 0.970 \\
\hline & Bilateral & & 1 & 0.1 & 1 & 0.1 & 2 & 0.1 & NS & 0.957 \\
\hline \multirow[t]{3}{*}{ Scissors bite } & \multirow{2}{*}{ Unilateral } & right & 2 & 0.2 & 0 & 0.0 & 2 & 0.1 & NS & 0.949 \\
\hline & & left & 1 & 0.1 & 1 & 0.1 & 2 & 0.1 & NS & 0.889 \\
\hline & Total & & 1125 & 100 & 1204 & 100 & 2329 & 100 & & \\
\hline
\end{tabular}

NS: Not significant. 
The prevalence of Class II Division 1 (40.0\%) in the present study was greater than the rates reported by Onyeaso ${ }^{17}$ (12.3\%), Thilander et $\mathrm{al}^{3}(14.9 \%)$, Haynes ${ }^{25}$ (12.5\%), Silva and Kang ${ }^{22}$ (20.3\%), and Foster and Day ${ }^{26}$ (27.2\%). Compared with the data from the American, Asian, Australian, and European populations, ${ }^{27}$ the Anatolian sample also showed a relatively high prevalence of Class II malocclusions. Lauc ${ }^{28}$ found that Class II malocclusion was more common in their population $(45.1 \%)$, and explained this figure by a genetic influence on the incidence of Class II malocclusions.

The prevalence of Class II Division 2 (4.7\%) in the present study complied with Thilander et al $^{3}$ (5.9\%), but greater than the rates reported by $0 n-$ yeaso $^{17}(1.4 \%)$ and Silva and Kang ${ }^{22}(1.2 \%)$.

The prevalence of Class III malocclusion $(10.3 \%)$ determined in this study is very close to the rates determined by Silva and $\mathrm{Kang}^{22}$ and Onyeaso, ${ }^{17} 9.1 \%$ and $11.8 \%$, respectively. However, Goose et $\mathrm{al}^{29}(2.91 \%)$, Haynes ${ }^{25}(2.5 \%)$, Foster and Day $^{26}(3.5 \%)$, Proffit et $\mathrm{al}^{24}(5.7 \%)$, Thilander et $\mathrm{al}^{3}$ $(5.8 \%)$ and $\operatorname{Lauc}^{28}(4.8 \%)$ reported lower rates.

The present study confirmed that the predomi- nant antero-posterior relationship of the arches in Turkish adolescents was Class II Division 1.

Of the vertical anomalies, increased overbite was more than twice as frequent as anterior open bite. Our results were similar to the rates reported by Thilander et $\mathrm{al}^{3}$ and Lauc ${ }^{28}$ who also reported a deep bite was often associated with a Class II malocclusion and more common in boys. But, Onyeaso ${ }^{17}$ reported a lower rate of deep bite, but higher rate of Class I malocclusion in their population.

Increased overjet showed high percentage as increased overbite in this study; this is a reflection of the higher prevalence of Class II malocclusion among Central Anatolian Turks. Our findings agree with those of Thilander et $\mathrm{al}^{3}$ in Bogotanian adolescents and Ciuffolo et $\mathrm{al}^{10}$ in Italian adolescents where high rates of increased overjet in the permanent dentition were reported. In a Nigerian population, Onyeaso ${ }^{17}$ stated that increased overjet was not as great as it was in white people.

In this study, uni/bilateral posterior crossbite was more frequent than scissor bite and was observed in $9.5 \%$ of the sample. This rate was similar to the findings of Ciuffolo et $\mathrm{al}^{10}{ }^{10}$ was higher than

Table 5. Distribution of anterior crowding.

\begin{tabular}{|c|c|c|c|c|c|c|c|c|c|}
\hline & \multirow{2}{*}{ Crowding } & \multicolumn{2}{|c|}{ Boys } & \multicolumn{2}{|c|}{ Girls } & \multicolumn{2}{|c|}{ Total } & \multirow{2}{*}{\multicolumn{2}{|c|}{$P$}} \\
\hline & & $\mathrm{n}$ & $\%$ & $\mathrm{n}$ & $\%$ & $\mathrm{n}$ & $\%$ & & \\
\hline \multirow[t]{2}{*}{ No crowding } & & 383 & 34.0 & 428 & 35.5 & 811 & 34.8 & NS & 0.460 \\
\hline & mild & 140 & 12.4 & 120 & 10.0 & 260 & 11.2 & NS & 0.214 \\
\hline \multirow[t]{3}{*}{ Only upper arch } & moderate & 55 & 4.9 & 60 & 5.0 & 115 & 4.9 & NS & 0.732 \\
\hline & severe & 18 & 1.6 & 24 & 2.0 & 42 & 1.8 & NS & 0.810 \\
\hline & mild & 67 & 6.0 & 70 & 5.8 & 137 & 5.9 & NS & 0.845 \\
\hline \multirow[t]{3}{*}{ Only lower arch } & moderate & 28 & 2.5 & 31 & 2.6 & 59 & 2.5 & NS & 0.760 \\
\hline & severe & 8 & 0.7 & 9 & 0.7 & 17 & 0.7 & NS & 0.77 \\
\hline & mild & 280 & 24.9 & 303 & 25.2 & 583 & 25.0 & NS & 0.981 \\
\hline \multirow[t]{2}{*}{ Both arches } & moderate & 127 & 11.3 & 137 & 11.4 & 264 & 11.3 & NS & 0.831 \\
\hline & severe & 19 & 1.7 & 22 & 1.8 & 41 & 1.8 & NS & 0.985 \\
\hline Total & & 1125 & 100 & 1204 & 100 & 2329 & 100 & & \\
\hline
\end{tabular}

NS: Not significant.

Table 6. Distribution of maxillary median diastema.

\begin{tabular}{lcccccccc} 
& \multicolumn{3}{c}{ Boys } & \multicolumn{2}{c}{ Girls } & \multicolumn{2}{c}{ Total } & \multirow{2}{*}{$\mathrm{P}$} \\
\cline { 2 - 7 } Midline diastema & $\mathrm{n}$ & $\%$ & $\mathrm{n}$ & $\%$ & $\mathrm{n}$ & $\%$ & & \\
\hline Absent & 1055 & 93.8 & 1110 & 92.2 & 2165 & 93.0 & NS & 0.385 \\
Present & 70 & 6.2 & 94 & 7.8 & 164 & 7.0 & NS & 0.385 \\
Total & 1125 & 100 & 1204 & 100 & 2329 & 100 & & \\
\hline
\end{tabular}

NS: Not significant. 
Thilander et al. ${ }^{3}$

Crowding in the anterior segment of one or both arches was the most frequent of all anomalies recorded (65.2\%). This finding complied with the results of Thilander et $\mathrm{al}^{3}$ and Lauc. ${ }^{28}$ Nevertheless, other studies have reported lower rates of anterior crowding located in the mandibular anterior segment. ${ }^{17,25,26}$ However, anterior crowding was greater in the upper arch than the lower arch, in this study. The National Health and Nutrition Survey III undertaken in the United States between 1989 and 1994 showed a frequency of crowding ranging from $42.3 \%$ at ages $8-11$ to $54.5 \%$ at ages 12-17 which was lower than the frequencies observed in this investigation. ${ }^{24}$

Thilander et $\mathrm{al}^{3}$ found the prevalence of median diastema in their population to be $13.5 \%$ in the early mixed and $4 \%$ in the permanent dentition. Lauc ${ }^{28}$ observed a high rate of midline diastema $(45.1 \%)$. In contrast, this rate for our study was $7 \%$ and the frequency of diastema in Nigeria was $24 \% .{ }^{17}$ Onyeaso indicated that diastema is not regarded as a malocclusion among Nigerians but as a mark of natural beauty. ${ }^{17}$

It is obvious that several genetic and environmental interacting factors are related to the aetiology of malocclusions. Soft diet, mouth breathing, tongue trusting, sleeping posture, sucking, and other habits as well as specific factors (skeletal growth disturbances, muscle dysfunction, disturbances in embryologic and dental development) interact with heredity in the development of major types of malocclusion. ${ }^{24}$ The difficulty in separating these factors is obvious: in terms of gene-environment interactions, intraoral environmental change may be a decisive factor but this change may also reveal previously masked genetic effects. ${ }^{30}$

\section{CONCLUSIONS}

The results of this investigation show that Class II Division 1 malocclusion is the most prevalent occlusal pattern among Central Anatolian adolescents and the high values of increased overjet and overbite are a reflection of the high prevalence of Class II malocclusion. In relation to gender, girls had significantly more normal overbite than the boys while boys significantly had more increased overbite than the girls. It is proposed that the genetic influence on development of these occlusal attributes in the connatural population of Anatolia should be the subject of future investigations. Further studies are required to clarify the findings and to provide accurate estimates of the orthodontic treatment need in Turkish adolescents.

\section{REFERENCES}

1. Trottman A, Elsbach HG. Comparison of malocclusion in preschool black and white children. Am J Orthod Dentofacial Orthop 1996;110:69-72.

2. de Muniz BR. Epidemiology of malocclusion in Argentine children. Community Dent Oral Epidemiol 1986;14:221-224.

3. Thilander B, Pena L, Infante C, Parada SS, de Mayorga C. Prevalence of malocclusion and orthodontic treatment need in children and adolescents in Bogotá, Colombia. An epidemiologic study related to different stages of dental development. Eur J Orthod 2001;23:153-167.

4. Kerosuo H. Occlusion in the primary early mixed dentitions in a group of Tanzanian and Finnish children. Eur $J$ Orthod 1990;57:293-298.

5. Tschill P, Bacon W, Sonko A. Malocclusion in the deciduous dentition of Caucasian children. Eur J Orthod 1997;19:361367.

6. Isiekwe MC. Malocclusion in Lagos, Nigeria. Community Dent Oral Epidemiol 1983;11:59-62.

7. Kerosuo H, Laine T, Kerouso E, Ngassapa D, Honkala E. Occlusion among a group of Tanzanian urban schoolchildren. Community Dent Oral Epidemiol 1988;16:306-309.

8. Brunelle JA, Bhat M, Lipton JA. Prevalence and distribution of selected occlusal characteristics in the US population, 1988-1991. J Dent Res 1996;75:706-713.

9. Otuyemi OD, Ogunynka A, Dosumu O, Cons NC, Jeny J. Malocclusion and orthodontic treatment need of secondary school students in Nigeria according to the Dental Aesthetic Index (DAI). Int Dent J 1999;49:203-210.

10. Ciuffolo F, Manzoli L, D’Attilio, Tecco S, Muratore F, Festa F, Romano F. Prevalence and distribution by gender of occlusal characteristics in a sample of Italian secondary school students: a cross-sectional study. Eur J Orthod 2005;27:601-606.

11. Rudan I, Campbell H, Rudan P. Genetic epidemiological studies of eastern Adriatic islands isolates, Croatia: objectives and strategies. Coll Antropol 1999;23:531-546.

12. Tang ELK, Wei SHY. Recording and measuring malocclusion: A review of the literature. Am J Orthod Dentofacial Orthop 1993;103:344-351.

13. Helm S. Malocclusion in Danish children with adolescent dentition: an epidemiologic study. Am J Orthod 1968:54:352366.

14. Infante PF. Malocclusion in the deciduous dentition in 
White, Black and Apache Indian children. Angle Orthod 1975;45:213-218.

15. Kristneli M, Shim YS. Malocclusion, body posture, and temporomandibular disorder in children with primary and mixed dentition. J Clin Pediatr Dent 1992;16:86-93.

16. McLain JB, Proffit WR. Oral health status in the United States: prevalence of malocclusion. J Dent 1985;49:386397.

17. Onyeaso CO. Prevalence of malocclusion among adolescents in Ibadan, Nigeria. Am J Orthod Dentofacial Orthop 2004;126:604-607.

18. Güray E, Orhan M, Ertas, E, Doruk C. Konya yöresi ilkokul çocuklarında Treatment Priority Index (TPI) uygulaması (Epidemiyolojik Calisma). Turk Ortodonti Derg 1994;7:195200.

19. Gelgor IE, Sișman Y, Malkoç S. Daimi dentisyonda konjenital hipodonti ve boyut anomalisi gösteren dișlerin görülme sıklıḡı. Turk Klin J Dental Sci 2005;11:43-53.

20. Ugur T, Ciḡer S, Aksoy A, Telli A. An epidemiological survey using the Treatment Priority Index (TPI). Eur J Orthod 1998;20:189-193.

21 Angle EH. Classification of malocclusion. Dental Cosmos 1899;41:248-264.

22. Silva RG, Kang DS. Prevalence of malocclusion among Latino adolescents. Am J Orthod Dentofacial Orthop 2001;119:313-315.

23. Tausche E, Luck O, Harzer W. Prevalence of malocclusion in the early mixed dentition and orthodontic treatment need. Eur J Orthod 2004;26:237-244.

24. Proffit WR, Fields HW Jr, Moray LJ. Prevalence of malocclusion and orthodontic treatment need in the United States: estimates from NHANES III survey. Int $J$ Adult Orthodon Orthognath Surg 1998;13:97-106.

25. Haynes S. The prevalence of malocclusion in English school children aged 11-12 years. Trans Eur Orthod Soc 1970;1:8998.

26. Foster TD, Day AJW. A survey of malocclusion and the need for orthodontic treatment in a Shrophire school population. Br J Orthod 1974;1:73-78.

27. Lombardi VA, Bailit H. Malocclusion in the Kwaio, a Melanesian group on Malaita, Solomon Islands. Am J Phys Anthropol 1972;36:283-294.

28. Lauc T. Orofacial analysis on the Adriatic islands: an epidemiological study of malocclusions on Hvar Island. Eur $J$ Orthod 2003;25:273-278.

29. Goose DH, Thompson DG, Winter FC. Malocclusion in school children of the West Midlands. Br Dent J 1957;102:174-
178.

30. Corruccini RS. Anthropological aspects of orofacial and occlusal variations and anomalies. In: Kelley M A, Larsen C S (eds) Advances in dental anthropology. Wiley-Liss, New York, pp. 1991; 295-323. 